WSRC-RP-92-925

\title{
INITIAL TECHNICAL BASIS FOR LATE WASHING FILTER CLEANING (J)
}

WSRC-RP- $-92-925$

by M. F. Morrissey

Westinghouse Savannah River Company

Savannah River Site

Aiken, South Carolina 29808

Other Authors:

L. O. Dworjanyn

(WSRC)
DE93 006791

This paper was prepared in connection with work done under Contract No. DE-AC09-89SR18035 with the U. S. Department of Energy. By acceptance of this paper, the publisher and/or recipient acknuwledges the U. S. Government's right to retain a nonexclusive, royalty-free license in and to any copyright covering this paper, along with the right to reproduce and to authorize others to reproduce all or part of the copyrighted paper.

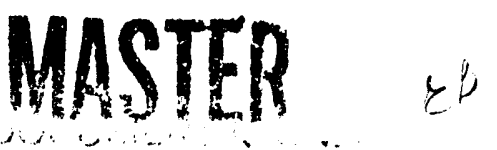






\section{DISCLAIMER}

This report was prepared as an account of work sponsored by an agency of the United States Government. Neither the United States Government nor any agency thereof, nor any of their employees, makes any warranty, express or implied, or assumes any legal liability or responsibility for the accuracy, completeness, or usefulness of any information, apparatus, product, or process disclosed, or represents that its use would not infringe privarely owned rights. Reference herein to any specific commercial product, process, or service by trade name, trademark, manufacturer, or otherwise does not necessarily constitute or imply its endorsement, recommendation, or favoring by the United States Government or any agency thereof. The views and opinions of authors expressed herein do not necessarily state or reflect those of the United States Government or any agency thereof.

This report has been reproduced directly from the best available copy.

Available to DOE and DOE contractors from the Office of Scientific and Technical Information, P.O. Box 62, Oak Ridge, TN 37831; prices available from (615) 576-8401, FTS 626-8401.

Available to the public from the National Technical Information Service, U.S. Department of Commerce, 5285 Port Royal Rd, Springfield, VA 22161. 
TO: E.W. HOLTZSCHEITER, 773-A

W.L. TAMOSAITIS, 773-A

FROM: L.O. DWORJANYN, 779-2A M.F. MORRISSEY, 676-T

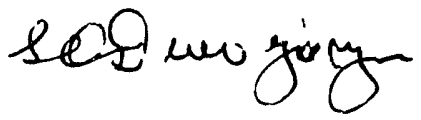


WSRC-RP-92-925

Pege 2

JuL 23, 1992

\section{SUMIARY}

Bench scale filter cleaning tests at the Savannah River Technology Center have shown that cross-flow filter elements can be cleaned between late wash filtration runs and restored to original clean water flux conditions. The most effective cleaning technique was high flow axial recirculation, followed by flushing with caustic solution. Simple flushing with oxalic acid and caustic is less effective and is not recommended because of adverse experience in ITP filter cleaning and uncertainty in the nature of radiolysis by-product contaminants.

\section{INTRODUCTION}

Radioactive cesium is removed from high activity waste salt solution by In-Tank Precipitation (ITP) with sodium tetraphenylborate. Strontium is also removed by adsorption with insoluble sodium titanate. The precipitate is concentrated, washed, stored, and subsequently hydrolyzed to break down the tetraphenylborate and release the aromatic carbon content of the slurry as benzene. Sodium nitrite is added during washing and precipitate storage to prevent pitting corrosion of the carbon steel storage tanks as the caustic concentration is reduced by washing.

Late Washing of the stored precipitate is being considered to remove most of the sodium nitrite inhibitor and the need for hydroxylamine nitrate (HAN) dixing hydrolysis, which results in subsequent accumulation of potentially explosive ammonium nitrate in the vessel vent system (Reference 1).

The proposed Late Washing process would be located in the Auxiliary Pump Pit, and would utilize the spare ITP filter (or other similar filter) for washing the precipitate, Figure 1. The late washing filtration task is comparable to ITP salt washing requirements (Reference 2). Lab tests (References 2 and 3) have shown that the filtration rate during late washing is about 35\% lower compared to fresh ITP filtration $10.09 \mathrm{vs} 0.14 \mathrm{gpm} / \mathrm{ft}^{2}$ at 30 psi and $6 \mathrm{ft} / \mathrm{sec}$ linear velocity). However, the available filtration cycle time during Late washing $(20 \mathrm{hrs}$ filtration/43 hr cycle) is larger than the available for ITP (26 days filtration/122 day cycle). Including the necessary waste water volume, this calculates to a late wash filtration rate requirement of $0.03 \mathrm{gpm} / \mathrm{ft}^{2}$ and for ITP $0.06 \mathrm{gpm} / \mathrm{ft}^{2}$ using one filter (Reference 2). While the lab tests on a single short filter tube shows adequate filtration rate compared to process requirements, the absolute values should be used with caution since the bench 
WSRC-RP-92-925

Page 3

July 23, 1992

tests permit more effective tube cleaning, back-pulsing and flow control (filter surface utilization) compared to a $10 \mathrm{ft} 144$ tube ITP filter bundle.

\section{EIITER CIEANING REOUIREMENTS}

During cross-flow filtration the permeate flow drops off rapidly as a filter cake builds up on the tube surface. Frequent backpulsing (reverse permeate flow) is used to lift the filter cake and restore the flow. However, as the filtration continues the pores plug with fines and the permeate flux gradually falls off necessitating filter cleaning to restore to original filter condition.

Recent ITP experience with full scale filters shows a water flux of onlv 20-30\% compared to bench scale measurements, even after repeated oxalic acid cleaning. We also know that during storage the precipitate ages by radiolysis, resulting in lower viscosity, smaller particle size, numerous organic decomposition products from the tetraphenylborate, and elemental mercury. To assure sustained filter capacity it is essential to develop cleaning techniques which will restore filter flux to original conditions.

\section{CLEANING TECHNIOUES - FLUX RECOVERY}

A series of cleaning tests were conducted using: (1) high velocity ( $6 \mathrm{ft} / \mathrm{sec}$ ) axial recirculation of the cleaning solutions and (2) slow flushing, equivalent to soaking the filter in the cleaning solution (Reference 4). A full set of filtration tests were run followed by different cleaning techniques. Each filtration test consisted of 11 processing conditions covering 15 to $45 \mathrm{psi}$ pressure and 2 to $10 \mathrm{ft} / \mathrm{sec}$ linear velocity (Reference $2)$. Three central repeat conditions ( $30 \mathrm{psi}, 6 \mathrm{ft} / \mathrm{sec})$ were used to gage the filtration rate and cleaning recovery, Figure 2.

The best flux recovery occurred with oxalic acid and caustic recirculation, $0.005 \mathrm{gpm} / \mathrm{ft}^{2}$ improvement. Flushing with oxalic acid and caustic was less effective, $0.003 \mathrm{gpm} / \mathrm{ft}$. M-Pyrol and $\mathrm{KOH} / \mathrm{Triton}$ recirculation were least effective on their own. oxalic acid initiates hydrolysis of the residual precipitate and is the key to good cleaning. The caustic solution probably helps in cleaning organic deposits from radiolysis products.

It was not possible to judge absolute filter cleanliness between these runs since the precipitate is expected to degrade and change as it is continuously recycled through the system. 
WSRC-RP-92-925

Page 4

July 23, 1992

\section{CLEANING TECHNIOUES - CLEAN HATER FIUX}

Another way to measure filter recovery is clean water flux either in cross-flow mode or by closing the filter outlet (dead end).

Figure 3, Experiments $B$ to $F$, shows clean water after oxalic acid and caustic axial cleaning between flux measurement tests

(Reference 2). Experiments $G 1$ and $G 2$ show clean water flux after oxalic acid/caustic axial recirculation and flush. Both show good restoration to original filter conditions.

Figure 4 shows the water flux measurements in cross-flow mode and by dead-ending are about the same. The observed differences may be attributed to pressure gauge locations and accuracy. In all cases the clean water flux was restored to $8-9 \mathrm{gpm} / \mathrm{ft}^{2}$ at $25 \mathrm{psi}$, close to manufacturer specifications.

\section{CIEANING CYCIE DFMONSTRATION}

The cleaning techniques developed in this study will be modified to simulate actual filter operation in late washing with following goals:

(1) Retain maximum slurry concentration for transfer to DWPE, i.e. transfer the finished slurry before filter cleaning. This is important to keep DWPF batch capacity rate.

(2) Reuse oxalic acid and caustic to minimize waste volume. Oxalic acid can be replenished as the concentration decreases, or replaced when too high in dissolved solids or activity.

(3) Re-use the filter between cleaning solutions to minimize solution degradation, and return the rinse water to tank 48 or similar.

(4) Provide for gravity filter drainage, or other displacement technique to minimize contamination between operations.

A separate report will be written to address this detailed demonstration of the cleaning steps.

\section{RFFERENCES}

(1) D.L. Fish, L.F. Landon; "Initial Technical Bases - DWPF Late Washing Facility", 6/15/92, WSRC-RP-92-793. 
WSRC-RP-92-925

Page 5

July 23, 1992

(2) L.O. Dworjanyn, M.F. Morrissey; "Initial Technical Basis for the Use of Spare ITP Filter in DWPF Late Washing", 6/5/92, WSRC-RP-92-766.

(3) M.F. Morrissey; "Late Washing Filtration Technical Test Plan", 4/1/92, WSRC-RP-92-359. (4) M.F. Morrissey; "Experiment I Program Plan Report", 7/24/92,
SRT-LWP-92-110. 


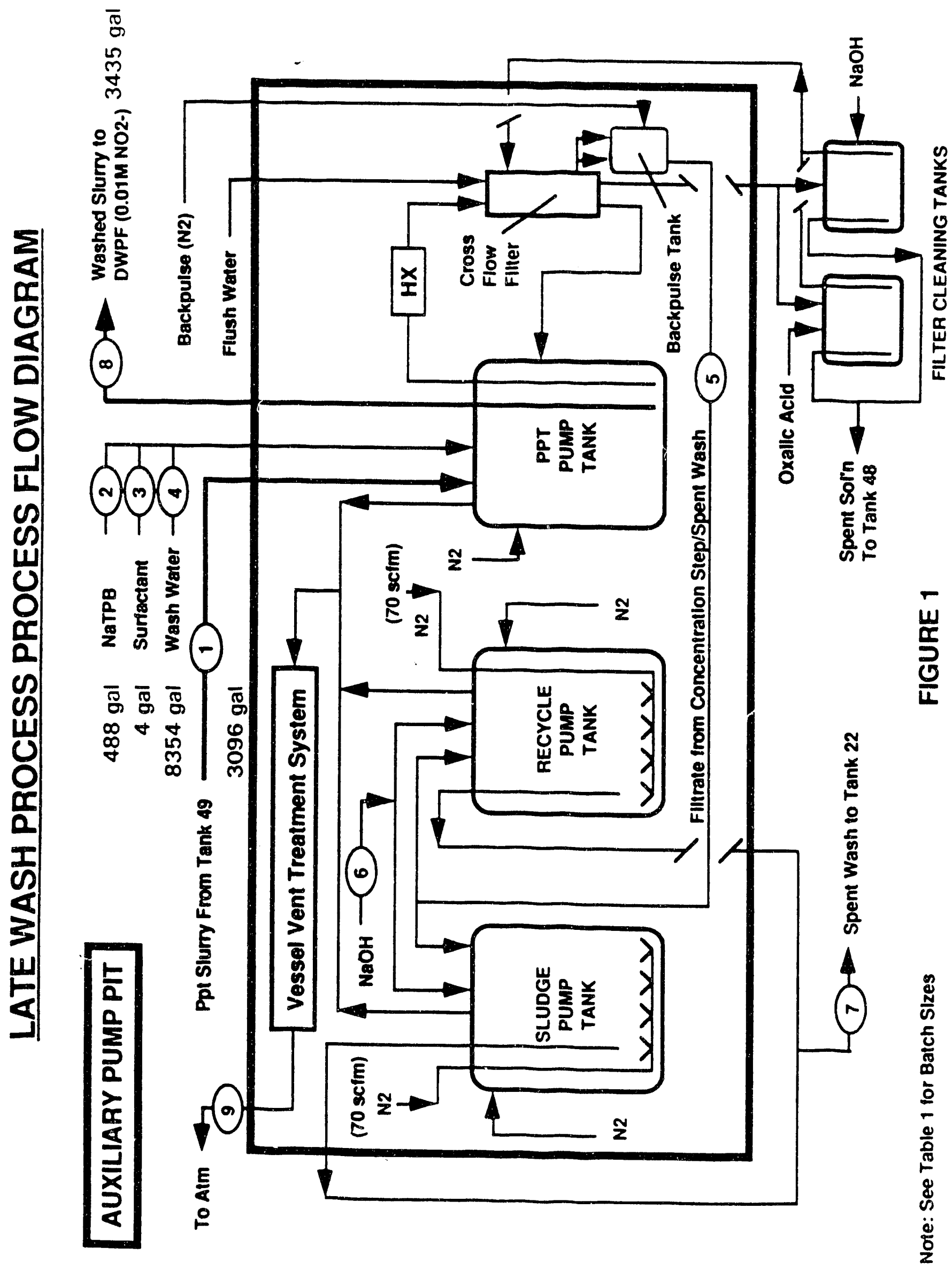




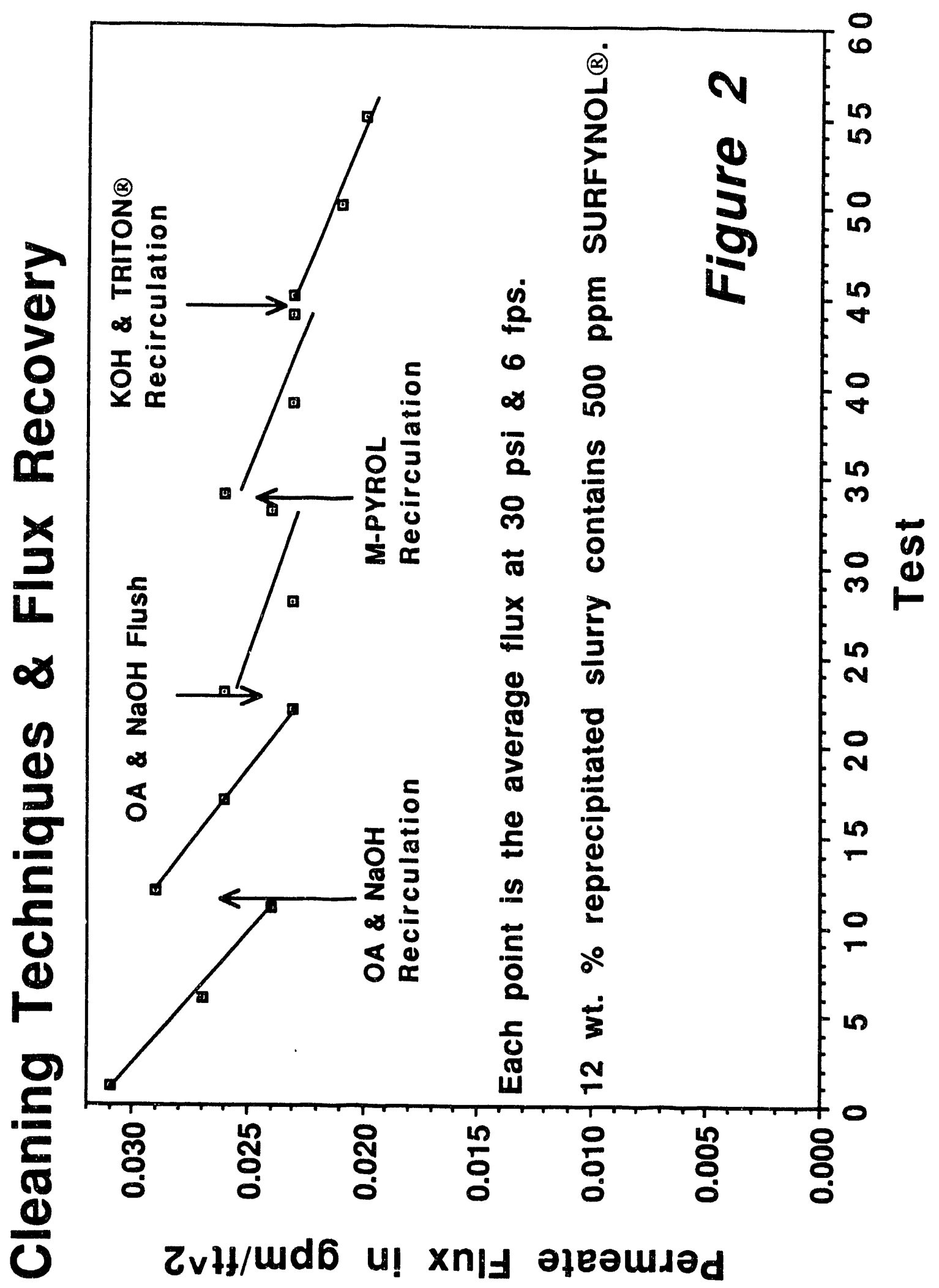




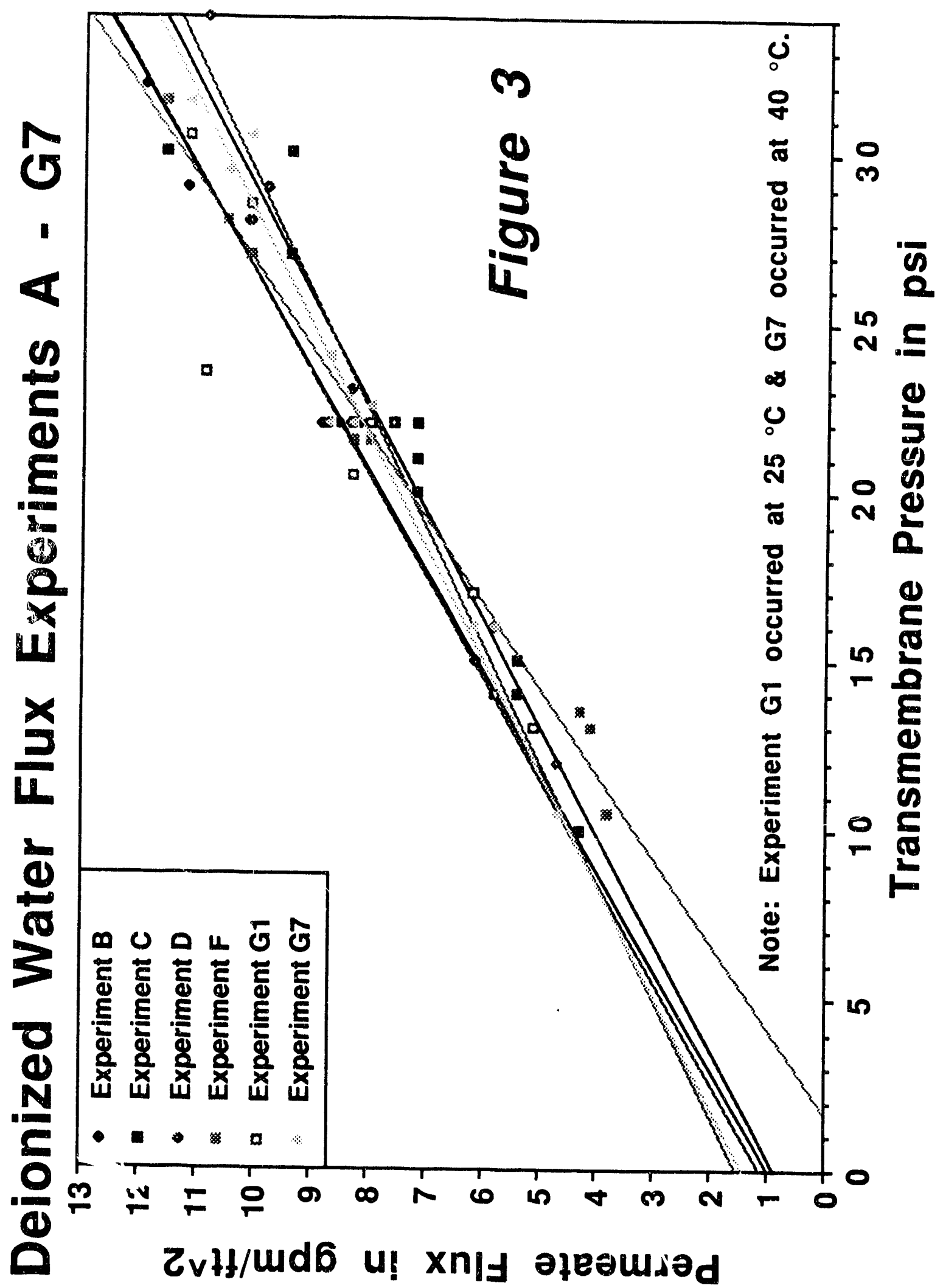




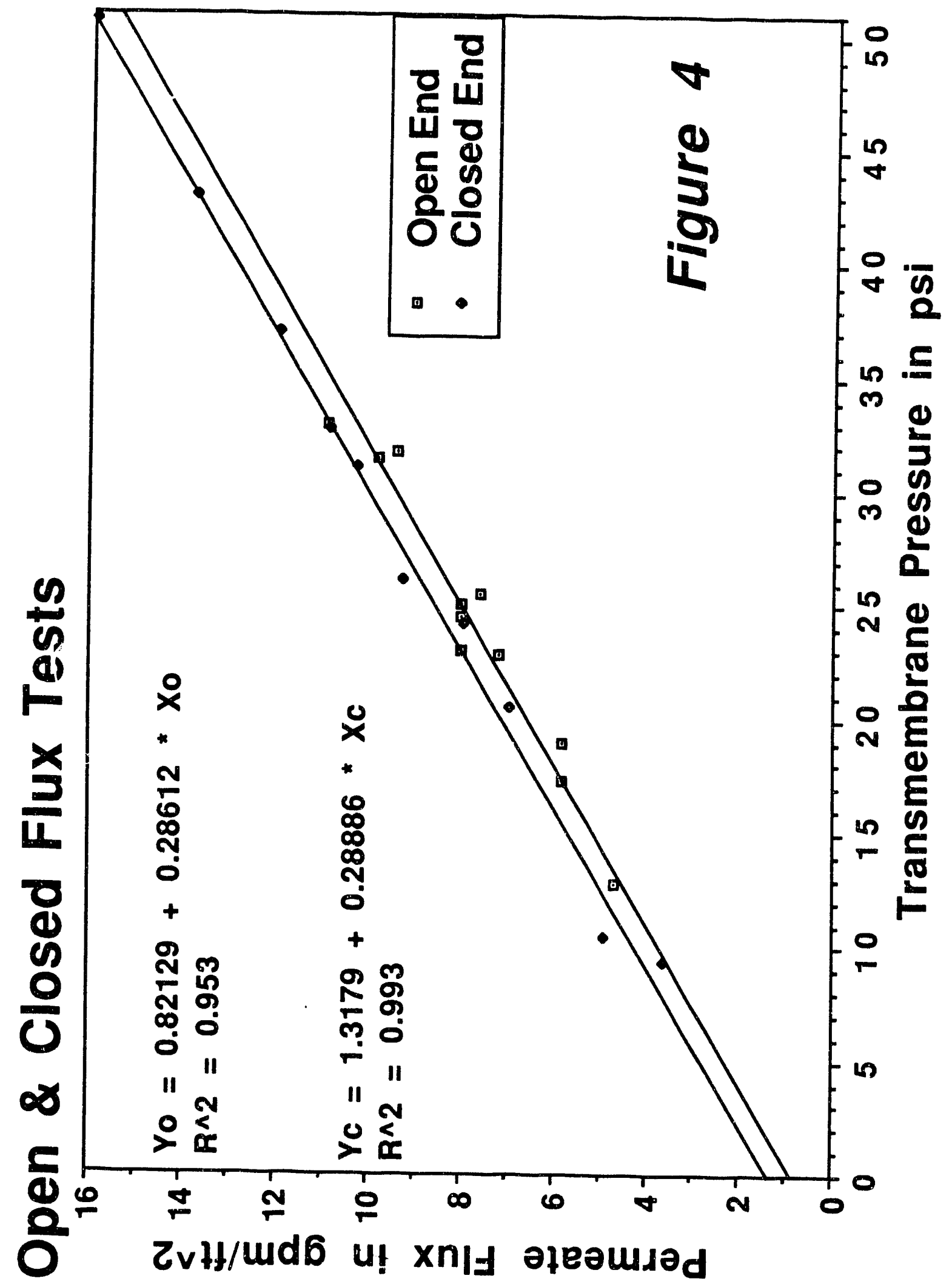



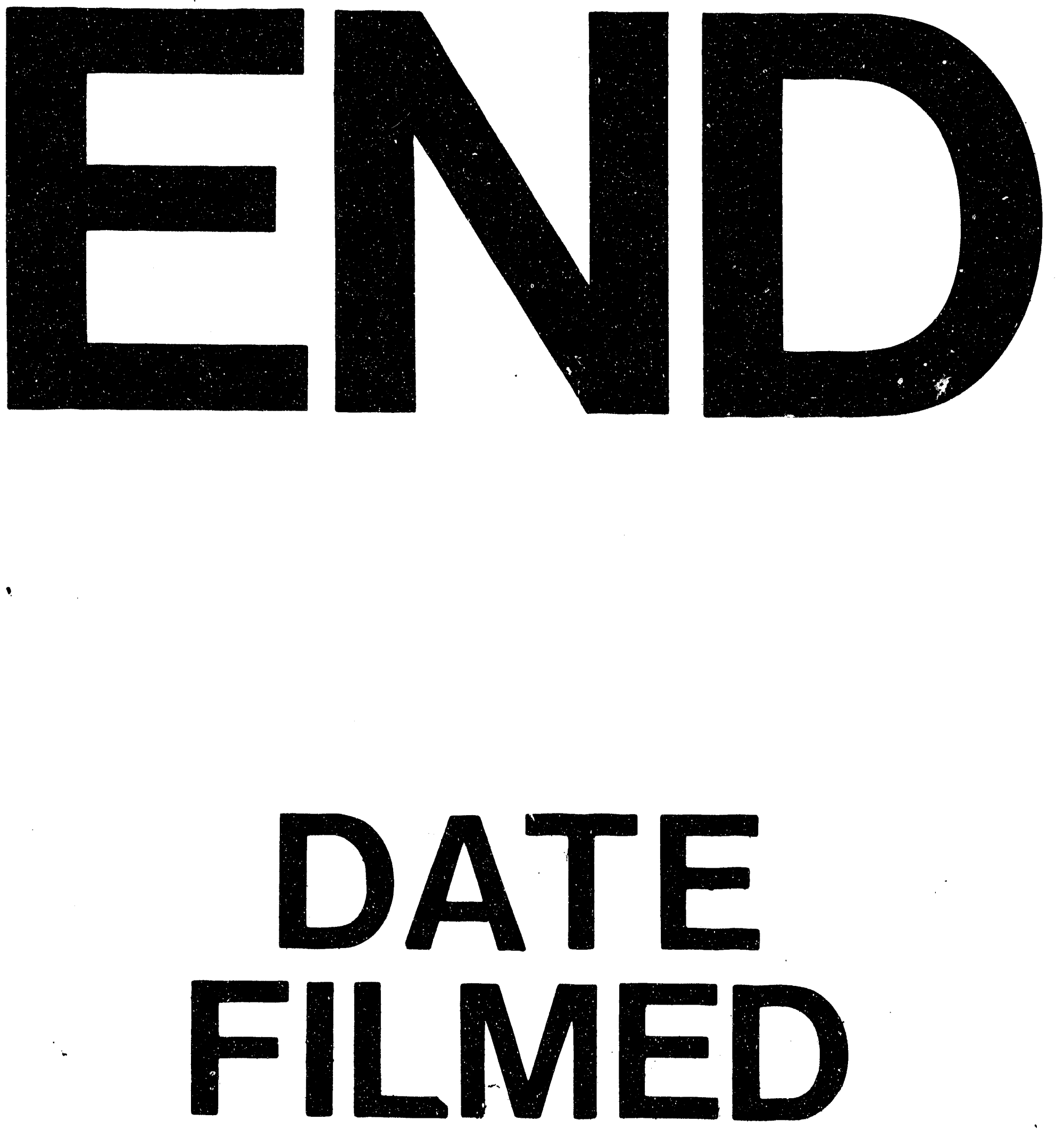

$$
420193
$$

